\title{
Why Does a Universal Anti-Bullying Program Not Help All Children? Explaining Persistent Victimization During an Intervention
}

\author{
Tessa M. L. Kaufman ${ }^{1} \cdot$ Tina Kretschmer $^{2} \cdot$ Gijs Huitsing $^{1} \cdot$ René Veenstra $^{1}$
}

Published online: 30 April 2018

(C) The Author(s) 2018

\begin{abstract}
Although anti-bullying interventions are often effective, some children continue to be victimized. To increase knowledge of potential factors that might impede children's benefiting from an anti-bullying intervention, we examined potential reasons for individual differences in victimization trajectories during a group-based anti-bullying intervention. Data stem from a five-wave survey among 9122 children (7-12 years old; grades $2-5)$ who participated in the KiVa anti-bullying intervention $(n=6142)$ or were in control schools $(n=2980$ children). Three trajectories were found in the intervention sample, representing children who experienced stable high, decreasing, or stable low/no victimization. A two-trajectory model of high and low trajectories represented the control sample best. Multinomial regressions on the intervention sample showed that children who experienced particularly high levels of peer rejection, internalizing problems, and lower quality parent-child relationships decreased less in victimization; thus these characteristics appeared to contribute to persistent victimization. The results call for tailored strategies in interventions aiming to reduce victimization for more children.
\end{abstract}

Keywords Anti-bullying intervention · Persistent victimization · Group-based trajectories · Risk characteristics

Bullying is a common phenomenon that exacts high costs for individuals and society, such as long-lasting health, wealth, and social consequences for victims, including psychiatric illness, educational difficulties, and poor relationships with parents and peers (Copeland et al. 2013; Brendgen and Poulin 2018; Kretschmer et al. 2018). The growing awareness of the prevalence and negative consequences of school bullying has amplified the development of interventions, many of which are schoolwide and focus on the peer group (Ttofi and Farrington 2011).

Effective school-wide anti-bullying interventions decrease bullying and victimization in primary schools to some extent (Evans et al. 2014; Merrell et al. 2008; Ttofi and Farrington

Electronic supplementary material The online version of this article (https://doi.org/10.1007/s11121-018-0906-5) contains supplementary material, which is available to authorized users.

Tessa M. L. Kaufman t.m.1.kaufman@rug.nl

1 Department of Sociology and Interuniversity Center for Social Science Theory and Methodology (ICS), University of Groningen, Groningen, the Netherlands

2 Department of Pedagogy and Educational Science, University of Groningen, Groningen, the Netherlands
2011). On average, $50 \%$ of interventions reported decreases in perpetration, and $67 \%$ reported decreases in victimization (Evans et al. 2014). Other positive intervention effects include increased knowledge about bullying, stronger anti-bullying attitudes (Merrell et al. 2008), and improved defending skills (Kärnä et al. 2011).

Nonetheless, it has become evident that some children are still victimized despite involvement in a universal schoolbased bullying intervention. For example, the prevalence of self-reported victimization at post-assessments was $23.3 \%$ 1 month after the termination of the Fear Not! intervention (Sapouna et al. 2010), and 19.2\% 2 years after the implementation of CAPSLE (Fonagy et al. 2009). Evaluations of the KiVa intervention (Salmivalli et al. 2011) also demonstrated that rates of victimization did not decrease to zero: out of the total sample, $8.9 \%$ of children in Finland (Kärnä et al. 2011) and $12.7 \%$ of Dutch children (Veenstra 2015) were still being victimized 1 and 2 years, respectively, after the intervention started. Such persistent victims may even be worse off after an intervention that results in the discontinued victimization of other children, as they lose "equals," that is, other children who were victims at the start of the intervention, in the classroom and they might blame themselves for their continued victimization (Garandeau et al. 2018). It is crucial to elucidate 
individual-level differences in intervention responsiveness and explore why some victims of bullying are helped whereas some others are not. To this end, we documented stability and change in victimization during and after an anti-bullying intervention (KiVa; Salmivalli et al. 2011) and examined theoretically meaningful predictors of individual differences in responsiveness.

\section{Obstacles to Intervention Effects}

Group-based interventions, including KiVa, emphasize that bullying is a group phenomenon; the aim is to increase empathy for victims, and develop bystanders' efficacy to counteract bullying in safe ways, so that more students disapprove of bullying and stand up for victims (Saarento et al. 2014). However, targeting peer dynamics still implies that victimized children possess qualities that make them desirable as friends. There are individual differences in the extent to which children are desirable to befriend, because some children score high on characteristics that are undesirable to others and low on desirable characteristics (Poulin and Chan 2010).

Social standing is one characteristic that makes some children more likely to recruit support than others. Peers are less likely to support victims who have a low social standing (Juvonen and Galván 2008), expressed as being unpopular and rejected. Popularity refers to visibility, prestige, or dominance in the peer group; being closely affiliated with popular peers is associated with high popularity for oneself (Marks et al. 2012). Vice versa, it can be risky to affiliate with unpopular children, because this enhances the risk of decreasing one's own status (Juvonen and Galván 2008). Therefore, peers might be less likely to support unpopular victims regardless of whether an anti-bullying program has been implemented. In addition to being unpopular, being rejected, thus being disliked by a large proportion of peers, also makes it difficult to recruit peers for support as children are less likely to support victims they reject (Thornberg et al. 2012). In short, although anti-bullying interventions aim to devalue pro-bullying behavior, victims' popularity or rejection are not targeted, thus being highly unpopular and rejected may negatively influence peers' willingness to step in.

Other feasible antecedents of individual differences in being desirable to support and befriend are direct (child) and indirect (parent-child relationships) factors. For instance, some children may be "awkward," withdraw from social interactions, or elicit negative responses from others (e.g., Hodges and Perry 1999). Such hurdles to social interaction can include low self-esteem but also internalizing or externalizing problems and low self-control.

Low self-esteem (Graham and Juvonen 1998; Guerra et al. 2011; Salmivalli and Isaacs 2005) is associated with submissive and socially disengaged interaction styles. Internalizing behaviors include social withdrawal, crying easily, and being anxious, all of which may impede social interactions. Externalizing behaviors (Reijntjes et al. 2011) such as being aggressive and having difficulties controlling emotions, behaviors, and desires in the face of external demands (Giesbrecht et al. 2011) can cause tension among peers. These child characteristics might decrease children's likelihood of recruiting supportive peers (Hodges and Perry 1999), and hinder their benefitting from the intervention.

Parent-child relationships might be more indirect sources of children's potential to recruit supportive peer relationships, thus benefit from the intervention. Social learning (Bandura 1971) and attachment theory (Bowlby 1969) agree that children who are socialized by cold, indifferent, and hostile parents learn fewer adaptive social strategies. They may learn that they are powerless, have less confidence, and be less well able to assert their needs (Duncan 2004), which could interfere with the creation of supportive contacts between victims and their peers, as encouraged by the intervention. Thus, it is feasible that children who are subjected to cold and hostile parenting are more likely to experience continued victimization. Understanding the role of the family context is especially relevant because group-based interventions do not usually focus on the parents (Axford et al. 2015). However, knowledge of the role of parent-related factors in predicting whether children benefit from an anti-bullying intervention could inform future efforts for including a parental component. Programs have been shown more effective when they address multiple contexts like the family context (Ttofi and Farrington 2011).

\section{Current Study}

It has been shown consistently that several children continue to be victimized post-intervention, but explanations for individual differences in intervention responsiveness are rare. Therefore, we examined theoretically meaningful predictors of persistent victimization, focusing on characteristics thought to impede children's social interactions with peers and ability to recruit defenders. We used data from the Dutch KiVa intervention, a longitudinal study following children for 2 years (five waves), beginning before the start of the intervention. We conducted analyses using a mixed approach to identify unobserved groups, such as persistent and non-persistent victims, both in the control and the intervention samples. We expected to find three trajectory groups in the intervention sample. First, the majority of children were unlikely to be victimized, and thus should constitute a "stable low" or non-involved group. Second, after the implementation of an intervention, we expected a group of children to show high initial levels of victimization which decrease over time, reflecting the intervention effect. Third, we expected to identify a group of persistent victims - those not helped by the intervention as observed 
when comparing pre-post scores - with persistently high victimization levels. With respect to the control sample, we expected two relatively stable groups: those who were victimized and those who were not.

We next examined whether social standing, child characteristics, and parent-child relationships varied between victims and non-victims, and, in the intervention sample, across the different expected victimization trajectories. We hypothesized a greater prevalence of persistent victimization in children with lower popularity and higher peer rejection, low self-esteem, higher internalizing and externalizing problems, lower self-control, lower levels of parental warmth, and higher levels of parental rejection. We also explored whether boys and girls differed in stability and change in victimization and predictors of persistent victimization.

\section{Methods}

\section{Participants and Procedure}

The data used in this study came from the Dutch implementation of the KiVa anti-bullying program. KiVa provides materials to teachers from grades 3-6. These include lesson plans, discussion ideas, and suggestions for group work and role-playing, in which children are encouraged to stand up against bullying and support victims (Salmivalli et al. 2011). Further, parents receive an information guide about bullying, a school-wide KiVa team is installed to resolve existing cases of bullying, and throughout the school symbols are used, such as posters and highly visible recess vests for teachers, to remind students and school personnel of KiVa. Although previous research has established the effectiveness of the intervention in Finland (Kärnä et al. 2011) and the Netherlands (Veenstra 2015), knowledge about victimization trajectories after implementation of the intervention is lacking. The longitudinal evaluation data of the Dutch KiVa were used: children were followed from before the start of the intervention for 2 years, resulting in five data waves (T1 = May 2012 - the intervention started in August, T2 = October 2012, T3 = May 2013, T4 = October 2013, T5 = May 2014).

Information about the study and consent forms were sent to parents prior to intervention implementation and assessments. Parents who did not want their child to participate in the assessment were asked to return the form. Students were informed at school about the research and gave oral assent. Both parents and students could withdraw from participation at any time. Students did not participate when parents refused participation, when they did not want to participate themselves, or when they were unable to complete the questionnaire. Non-response rates were low $(\mathrm{T} 1=0.6 \%$; $\mathrm{T} 2=0.2 \%$; $\mathrm{T} 3=0.5 \% ; \mathrm{T} 4=1.3 \% ; \mathrm{T} 5=2.7 \%$ ), largely because the data were collected digitally and students who missed the scheduled day of data collection could participate on another day within a month. Individual internet-based questionnaires were completed during regular school hours with primary teachers present to answer questions and assist students when necessary. The order of questions and instruments used was randomized to avoid systematic effects of question order. Assessments were identical in intervention and control conditions.

The intervention sample used here consisted of 6142 students in 65 schools ( $49.6 \%$ boys), with students in grades 2 5 at T1 $\left(M_{\text {age }}=9.14, S D=1.28\right)$. Students were $79.7 \%$ Dutch, 3.5\% Moroccan, 2.2\% Turkish, 2.5\% Surinamese, and 1.1\% Dutch Antillean. The remaining children reported another Western $(6 \%)$ or non-Western $(5.2 \%)$ ethnicity. The control sample consisted of 2980 students $(49.4 \%$ boys $)$ in 33 schools, with students in grades $2-5\left(M_{\text {age }}=9.22, S D=\right.$ 1.28). Students were $80.3 \%$ Dutch, $2.8 \%$ Moroccan, $1.8 \%$ Turkish, 2.5\% Surinamese, and 1\% Dutch Antilleans; $11.1 \%$ of students reported another Western (5.6\%) or non-Western (5.5\%) ethnicity.

\section{Measures}

Measures were similarly assessed in intervention and control schools. Assessments from all time points were used to measure victimization; the earliest available assessment was used for risk factors. Several measures were shortened or not included in the T1 questionnaire in order to limit the questionnaire length to the attention span of the children and the time available in the schools (45 min). The survey included selfreports and peer nominations. For the latter, children were presented with the names of all of their classmates and could select an unlimited number of classmates. Children could answer "nobody" when they did not want to select any classmates.

Victimization (T1-T5) was measured via self-reports using the Olweus' (1996) Bully/Victim Questionnaire. Children watched a movie in which bullying was defined (repeatedly harassing another child, and the victim has problems defending him or herself); after this, they responded to one global item ("How often have you been bullied during the past couple of months?") and seven specific items concerning physical, verbal (two items), relational (two items), material (i.e., taking or breaking others' property), and cyber victimization (i.e., receiving nasty or insulting messages, calls, or pictures). Children answered on a five-point scale ( $0=$ not at all, $1=$ once or twice, $2=$ two or three times $a$ month, $3=$ about once a week, 4 = several times per week). Scales were internally consistent at all time points ( $\alpha$ 's > .87).

Social anxiety (T2) was measured using a seven-item scale, derived from the Social Phobia Screening Questionnaire (Furmark et al. 1999). We used items from the original questionnaire that were appropriate for this age group, such as "I 
am scared to talk to someone whom I don't know" $(1=$ never, $5=$ always $)$. The items formed a reliable scale $(\alpha=.77)$.

Depressive symptoms (T2) were measured using nine ageappropriate items from the Major Depression Disorder Scale (Chorpita et al. 2000). Children responded on a four-point scale to items such as "I feel worthless" $(1=$ never to $4=$ always), $\alpha=.81$.

Externalizing behaviors (T2) were measured using 13 items from the Youth Self Report Conduct Problem Scale (Achenbach 1991). Several items were slightly modified to improve applicability to this age group. Students responded on a three-point scale to items such as "I break rules at school or elsewhere" ( $1=$ never to $3=$ often $), \alpha=.81$.

Self-control (T2) was measured using eight items from the Temperament in Middle Childhood Questionnaire (Simonds and Rothbart 2004) (e.g., "When someone tells me 'Stop', I can stop"). Students responded on a five-point scale ( $1=$ never to $5=$ always), $\alpha=.69$.

Self-esteem (T1) was measured using five items based on the Rosenberg Self Esteem Scale (Rosenberg 1965) (e.g., "On the whole, I am satisfied with myself"). Only positively formulated items were used. Students responded on a five-point scale $(1=$ never to $5=$ always $), \alpha=.82$.

Popularity (T2) was measured by asking students to nominate the classmates they perceived as most popular ("Who are the most popular students in your class?"). Rejection (T2) was measured by asking students to name the classmates they disliked ("Which classmates do you not like at all?"). For each student, received nominations were summed and divided by the number of participating classmates, resulting in proportion scores for popularity $(0-1)$ and peer rejection $(0-1)$.

Parental warmth and rejection (T2) were assessed using the EMBU Warmth and Rejection Scale (Arrindell et al. 1983). We used four items from the original subscales (i.e., warmth and rejection) referring to both father and mother. Students responded on a four-point scale ( $1=$ no to $4=$ almost always $)$ to questions such as "If things are not going right for you, does your father/mother try to comfort or help you?" (warmth) and "Is your mother/father sometimes harsh and unkind to you?" (rejection). The items formed reliable scales: maternal warmth $(\alpha=.85)$ and rejection $(\alpha=.73)$ and paternal warmth $(\alpha=.86)$ and rejection $(\alpha=.85)$. Answers for both parents were highly correlated, for warmth $(r=0.57, p<.001)$ and for rejection $(r=0.53, p<.001)$; thus, we used a composite.

\section{Attrition and Missing Data}

The initial sample consisted of 10,838 students: 7302 students in intervention schools and 3536 students in control schools. We excluded students with fewer than three data points on the victimization variable to obtain valid trajectories. Among the 1650 students who were excluded for this reason (intervention
1116, control 534), 1609 (intervention 1093, control 516) were excluded because they were not pupils at the school at the time of at least two assessments, because they were in the last grade of primary school (grade 8) at T1 and did not take part in later assessments, or because they entered grade 5 in T4 and thus did not participate in earlier assessments. We also excluded participants with missing data on all predictors, as was the case for a small number of children who entered the school at a later date. No evidence for differences between excluded and included children on predictor scores were found.

\section{Analyses}

Semi-parametric group-based models were used to identify the number and shape of distinct victimization trajectories using data from $\mathrm{T} 1$ to $\mathrm{T} 5$. The analyses proceeded in three steps. In the first step, we estimated the developmental models for victimization separately for control and intervention samples using latent class growth models in Mplus 7.1.4 (Muthén and Muthén 2015). We fitted a series of models beginning with a one-group model and moving to a four-group solution (cf. Barker et al., 2008a). All models were estimated with random starts, and variances within trajectories were constrained to zero. We estimated both linear and quadratic trajectories for each group. Bayesian Information Criterion (BIC), entropy, and Lo-Mendell-Rubin adjusted likelihood ratio test (LMR-LRT; Lo et al. 2001) were used to establish the best solution, and the theoretical meaningfulness of the best-fitting model was evaluated. Entropy was assessed to establish whether the most likely class membership could be used as grouping variable in subsequent analyses (>.91; Heron et al. 2015).

Next, we performed multinomial logistic regressions (using group membership as a dependent variable) to examine whether social standing, child characteristics, and relationships with parents influenced membership in trajectory groups. In all models, we controlled for children's sex and, wherever we detected significant associations with the outcome, investigated whether associations varied by sex. Missing data remaining after the case selection procedure outlined above were handled using full information maximum likelihood estimation. We computed intra-class correlations (ICC) of the manifest variables of victimization at the classroom level. About $6 \%$ of the differences in victimization were between classrooms $\left(\mathrm{ICC}_{\text {class }}=.064\right.$ at $\mathrm{T} 2$ and .057 at T5). Therefore, we used a multilevel structure in which we used the cluster command in Mplus to take into account the dependent structure of the data. We estimated univariate as well as multivariate prediction of trajectory groups to identify which characteristics predicted group membership, above and beyond the variance attributable to other predictors. 


\section{Results}

\section{Step 1: Trajectories}

The fit indices for the trajectory models in the intervention sample showed that the entropy of the two-group model (.945) was higher than that of the three-group model (.924), but BIC and LMR-LRT value indicated a better fit for the three-group model (two-group model BIC $=43,339.8$, LMRLRT <.001; three-group-model BIC $=40,988.1$, LMRLRT =.002). Although adding a fourth trajectory would have further improved the model according to the higher entropy value (.927), it would not according to the higher BIC value $(51,807.2)$ and LMR-LRT $(p=.727)$, and it would also have led to groups being too small to make meaningful group comparisons $(<3 \%$ of the sample; Haltigan and Vaillancourt 2014). Thus, we moved forward with the three-group model because this model was more parsimonious and allowed for a more meaningful interpretation.

The three trajectory groups (Fig. 1) describe persistent victimization $(3.6 \%)$, decreasing victimization $(15.3 \%)$, and no (or very low levels of) victimization $(81.1 \%)$. The persistent $\left(M_{\text {intercept }}=1.70\right)$ and decreasing $\left(M_{\text {intercept }}\right.$ $=1.64)$ trajectories did not differ in initial levels of victimization. The non-involved trajectory $\left(M_{\text {intercept }}=0.42\right)$ started with lower levels of victimization than both other trajectories $(p<.001)$. After the start of the intervention (T1), the development of victimization differed. In the persistent trajectory, victimization linearly increased $\left(M_{\text {lslope }}=0.35\right.$, $p=.010)$ and leveled off over time $\left(M_{\text {qslope }}=-0.09\right.$, $p=.013)$. In the decreasing trajectory, victimization linearly decreased $\left(M_{\text {lslope }}=-0.40, p<.001\right)$ and leveled off over time $\left(M_{\mathrm{qslope}}=0.03, p=.030\right)$. The non-involved trajectory had the same shape as the decreasing trajectory, but the decrease in victimization was less steep in the non-involved trajectory $\left(M_{\text {lslope }}=-0.17, p<.001 ; M_{\mathrm{qslope}}=0.02\right.$, $p<.001)$. Sex was not a significant predictor of trajectory membership, $\chi^{2}=1.96$ (2), $p=.375$.

With respect to the control sample, a two-group model showed the best fit. This model described one low (86.8\%) and one high $(13.2 \%)$ trajectory. In the low trajectory $\left(M_{\text {intercept }}=0.46\right)$, victimization linearly decreased $\left(\mathrm{M}_{\text {lslope }}=\right.$ $-0.15, p<.001)$ and leveled off over time $\left(\mathrm{M}_{\mathrm{qslope}}=0.02, p\right.$ $<.001)$. The high trajectory started with significantly elevated $(p<.001)$ levels of victimization $\left(M_{\text {intercept }}=1.80\right)$ and decreased with a non-significant trend $\left(M_{\text {lslope }}=-0.09\right.$, $\left.p=.174 ; M_{\mathrm{qslope}}=-0.03, p=.087\right)$. Despite the fit indices suggesting a two-trajectory solution, we also estimated a three-trajectory model, describing one stable-low (79.6\%), one medium (16.2\%), and one stable-high (4.3\%) trajectory. The medium trajectory $\left(M_{\text {intercept }}=1.80\right)$ showed a decreasing trend which was not significant, as indicated by the nonsignificant slope and quadratic effects $\left(M_{\text {lslope }}=-0.13\right.$, $p=.059 ; M_{\mathrm{qslope}}=-0.02, p=.220$ ). This overall pattern supports our expectation that KiVa would contribute to a decline in victimization, and justifies comparing the persistent and decreasing groups in the intervention condition only.

\section{Step 2: Univariate Predictions for Victimization Trajectories}

Means and standard deviations for victimization and predictors across trajectories are presented in Table 1 and correlations are presented in the Appendix (available online). Table 2 provides univariate estimates for the trajectory predictions. Contrasting victim trajectories (persistent and decreasing) with the non-involved trajectory shows that social standing, child characteristics, and problematic parent-child relationships predicted victimization (both persistent and decreasing) in both the intervention and the control sample.

Most relevant to our research question were predictions of membership in the persistent trajectory compared with the decreasing trajectory; for this we focused on the intervention sample (see first columns of Table 2). Membership in the persistent trajectory was more likely for children with high scores on peer rejection $(O R=1.15)$, social anxiety $(O R=1.35)$, depressive symptoms $(O R=1.36)$, and parental rejection $(O R=1.29)$, and a low score on parental warmth $(O R=0.74)$.
Fig. 1 Graphical representation of the victimization trajectories in the intervention sample (sample and estimated means). Lines represent the persistent trajectory (solid line; $3.6 \%$ ), the decreasing trajectory (dotted line; $15.3 \%$ ), and the non-involved trajectory (dashed line; $81.1 \%$ )

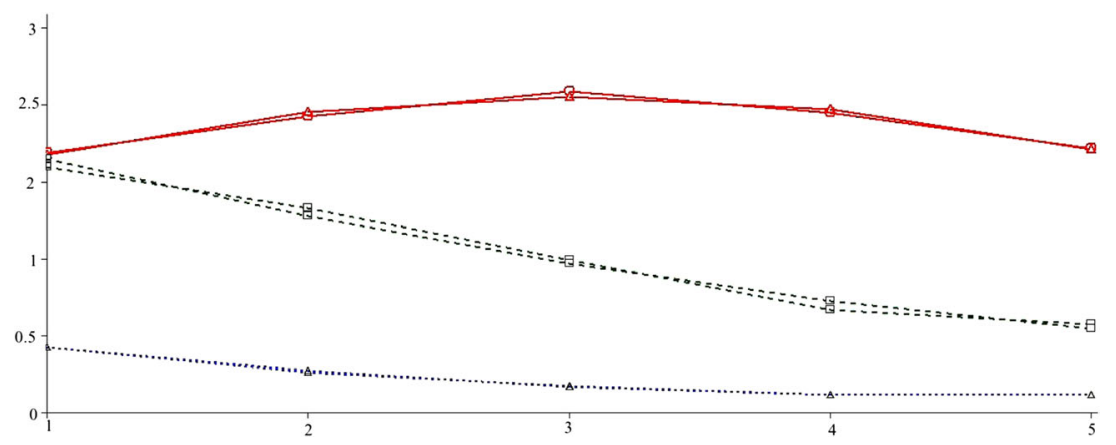


Table 1 Descriptive statistics of the model variables across trajectories in the intervention $(n=6.142)$ and control $(n=2.980)$ samples

\begin{tabular}{|c|c|c|c|c|c|}
\hline \multirow[b]{2}{*}{ Model variable (range) } & \multicolumn{3}{|c|}{ Intervention sample } & \multicolumn{2}{|c|}{ Control sample } \\
\hline & $\begin{array}{l}\text { Persistent } \\
(n=217) \\
\text { Estimates } \\
M(\mathrm{SD})\end{array}$ & $\begin{array}{l}\text { Decreasing } \\
(n=919) \\
\text { Estimates } \\
M(\mathrm{SD})\end{array}$ & $\begin{array}{l}\text { Non-involved } \\
(n=5006) \\
\text { Estimates } \\
M(\mathrm{SD})\end{array}$ & $\begin{array}{l}\text { High } \\
(n=386) \\
\text { Estimates } \\
M(\mathrm{SD})\end{array}$ & $\begin{array}{l}\text { Low } \\
(n=2594) \\
\text { Estimates } \\
M(\mathrm{SD})\end{array}$ \\
\hline \multicolumn{6}{|c|}{ Social standing and child characteristics } \\
\hline Popularity & $0.09(0.12)$ & $0.10(0.13)$ & $0.14(0.16)$ & $0.08(0.12)$ & $0.14(0.17)$ \\
\hline Peer rejection & $0.26(0.17)$ & $0.21(0.17)$ & $0.12(0.12)$ & $0.26(0.19)$ & $0.12(0.12)$ \\
\hline Self-esteem & $3.91(1.06)$ & $3.91(0.88)$ & $4.11(0.70)$ & $3.93(0.95)$ & $4.06(0.76)$ \\
\hline Social anxiety & $2.32(1.01)$ & $2.13(0.83)$ & $1.87(0.68)$ & $2.17(0.90)$ & $1.84(0.64)$ \\
\hline Depressive symptoms & $2.07(0.66)$ & $1.94(0.60)$ & $1.59(0.45)$ & $2.07(0.66)$ & $1.60(0.45)$ \\
\hline Externalizing behaviors & $1.33(0.35)$ & $1.29(0.29)$ & $1.19(0.20)$ & $1.30(0.33)$ & $1.20(0.21)$ \\
\hline Self-control & $3.50(0.56)$ & $3.57(0.51)$ & $3.73(0.47)$ & $3.52(0.53)$ & $3.71(0.47)$ \\
\hline \multicolumn{6}{|l|}{ Relationships with parents } \\
\hline Parental warmth & $3.11(0.83)$ & $3.30(0.71)$ & $3.48(0.62)$ & $3.28(0.76)$ & $3.45(0.63)$ \\
\hline Parental rejection & $1.81(0.65)$ & $1.71(0.58)$ & $1.47(0.45)$ & $1.72(0.62)$ & $1.48(0.45)$ \\
\hline
\end{tabular}

\section{Step 3: Adjusted Predictions for all Covariates for Victimization Trajectories}

Table 3 provides predictions for contrasts between the persistent and the decreasing victimization trajectories when adjusted for all other predictors. Higher peer rejection $(O R=1.16)$ and social anxiety $(O R=1.29)$, and lower parental warmth $(O R=0.74)$ continued to predict persistent victimization when all other risk factors were taken into account.

\section{Discussion}

The central aim of this study was to test whether social standing, child characteristics, and parent-child relationships explain why some children are persistently victimized despite participating in an anti-bullying intervention. Until now, explanations of individual differences in intervention effects have been limited to sex (e.g., Kärnä et al. 2011) and grade (Yeager et al. 2015). To our knowledge, there has been no research on individual differences in stability and change in victimization post-intervention.

Group-based trajectory analyses revealed heterogeneity in victimization trajectories both in control and intervention samples, with a small group of children being persistently victimized, one larger group for which victimization decreased over time, though (as expected) only within the intervention sample, and one large group remaining low or not involved in victimization over time. In support of previous findings on risk characteristics for victimization, all predictors in our model differentiated victims from non-victims. In addition, higher levels of peer rejection, internalizing behaviors (especially social anxiety), and lower-quality parent-child relationships (especially lower warmth) predicted persistent compared with decreasing victimization.

\section{Predicting Trajectories of Victimization}

Trajectory analyses revealed persistent, decreasing, and noninvolved victimization pathways in the intervention sample, mirroring previous research on victimization development in which the three-group model represented the best-fitting solution, with a small group of persistent victims, a larger group of individuals who were less victimized over time, and a large group of non-involved children (Barker et al., 2008b; Biggs et al. 2010; Boivin et al. 2010). In our sample, the group of children on a decreasing victimization pathway (15.3\%) seemed large compared with previous studies. Examples of the sizes of the decreasing victimization group in previous studies are $4.5 \%$ (Boivin et al. 2010), 6.6\% (Sheppard et al. 2018), and $10 \%$ (Barker et al., 2008a); in our own control sample, we only found a stable high group with a (nonsignificant) decreasing trend. The obvious explanation for the relatively large group of decreasers in the intervention sample is that our sample was drawn from an intervention study. The larger proportion of children who decreased in victimization reflects the overall effectiveness of the intervention. Nonetheless, we also detected the hypothesized persistent victimization group. The size of the persistent group in the current study was somewhat smaller than in other studies (Barker et al., 2008a; Sheppard et al. 2018). 


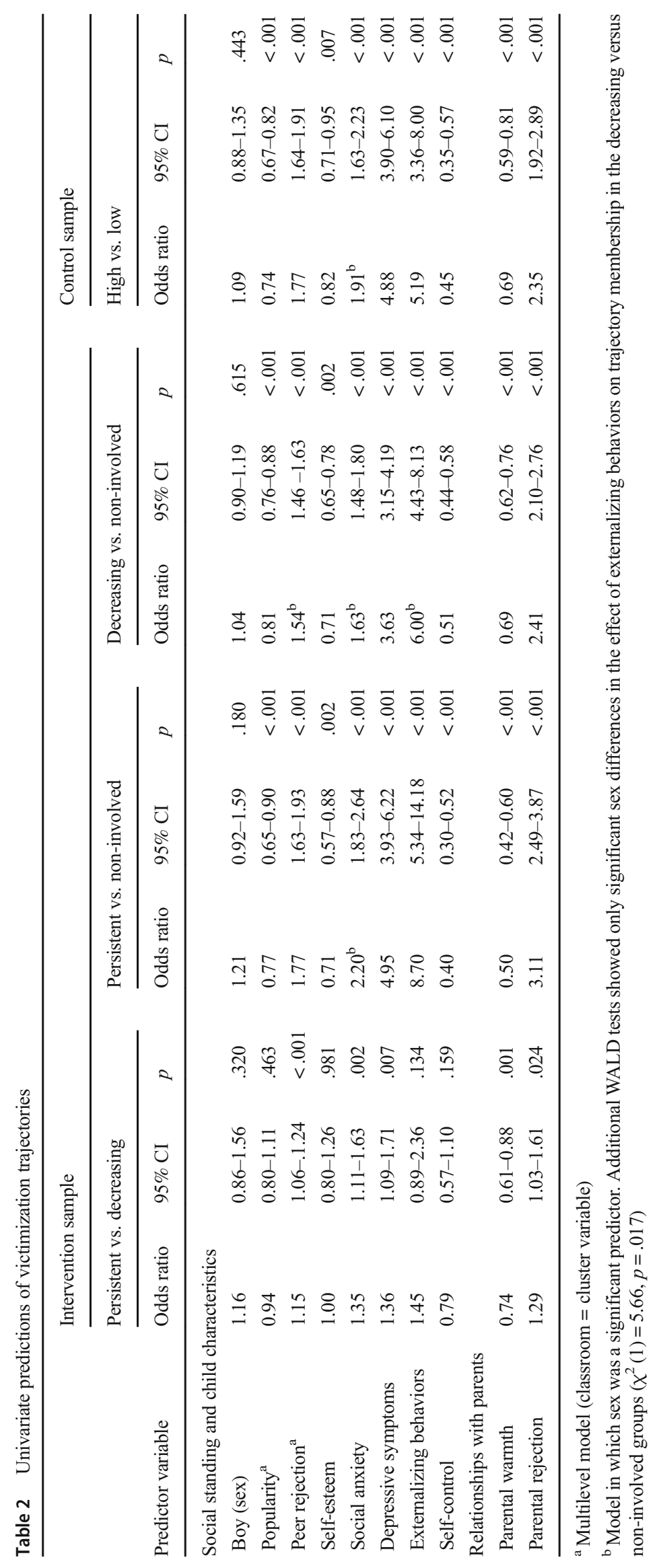


Table 3 For all covariates adjusted predictions for chronic versus decreasing trajectories in the intervention sample

\begin{tabular}{|c|c|c|c|}
\hline \multirow[b]{2}{*}{ Predictors } & \multicolumn{3}{|c|}{ Persistent vs. decreasing } \\
\hline & Odds ratio & $95 \% \mathrm{CI}$ & $p$ \\
\hline \multicolumn{4}{|c|}{ Social standing and child characteristics } \\
\hline Boy (sex) & 1.12 & $0.79-1.58$ & .527 \\
\hline Popularity & 1.05 & $0.92-1.19$ & .988 \\
\hline Peer rejection & 1.16 & $1.06-1.27$ & .001 \\
\hline Self-esteem & 1.07 & $0.91-1.29$ & .490 \\
\hline Social anxiety & 1.29 & $1.05-1.57$ & .014 \\
\hline Depressive symptoms & 1.29 & $0.98-1.71$ & .068 \\
\hline Externalizing behaviors & 0.91 & $0.54-1.34$ & .769 \\
\hline Self-control & 1.08 & $0.75-1.53$ & .776 \\
\hline \multicolumn{4}{|l|}{ Relationships with parents } \\
\hline Parental warmth & 0.74 & $0.60-0.92$ & .007 \\
\hline Parental rejection & 1.12 & $0.99-1.66$ & .061 \\
\hline
\end{tabular}

The model was a multilevel model (classroom = cluster variable)

In line with previous findings, victimization was predicted by higher levels of social anxiety and depressive symptoms (Reijntjes et al. 2010), peer rejection (Salmivalli and Isaacs 2005), externalizing behaviors (Reijntjes et al. 2011), and parental rejection (e.g., Barker et al., 2008b; Kokkinos 2013), and by lower levels of popularity (Cook et al. 2010), selfesteem (Graham and Juvonen 1998; Guerra et al. 2011; Salmivalli and Isaacs 2005), self-control (Giesbrecht et al. 2011), and parental warmth (e.g., Barker et al., 2008b; Kokkinos 2013). Thus, regardless of their role in an intervention, these characteristics can be regarded as risks for victimization. Most notably, several characteristics not only differentiated victims from non-victims but also contributed to greater vulnerability to continuing victimization despite participation in a group-based intervention. Lower levels of risk factors for persistent victimization also predicted decreasing victimization. Thus, children who experienced slightly elevated levels of individual risk factors may still be able to benefit from a group-based intervention. Children with highly elevated levels of these internalizing and parent-child relationship problems, however, have difficulties taking advantage of such an intervention. Future studies could further examine what factors can decrease the levels of risk factors within the intervention, for example targeting internalizing problems or problems in the family context, so all children can benefit from a universal intervention.

Peer rejection predicted persistent victimization, perhaps because rejected children can recruit support from fewer classmates, and peers gain little from supporting a rejected child in terms of affection or status, rendering the KiVa strategy somewhat less effective. Further, rejected children tend to be more reactive and angry, and less able to self-regulate during distressing social situations, including victimization (Morrow et al. 2014). Bystanders may not recognize victimization situations where victims show such behaviors, and thus refrain from defending.

In line with theoretical assumptions, internalizing behaviors also predicted persistent relative to decreasing victimization over time. It is feasible that socially anxious or depressed children more often withdraw from social interactions or are considered less interesting or desirable for others to interact with. In turn, they miss out on the increased opportunities to create supportive bonds with peers established in group-based interventions (Hodges and Perry 1999). Alternatively, children with internalizing problems might have a tendency to interpret social situations in a negative or threatening manner; they might thus perceive peers' behaviors as continued bullying (Miers et al. 2008) and be less likely to view their situation as improving.

Besides individual characteristics, children's relationships with parents were also associated with persistency, suggesting that children who experienced negativity in parent-child relationships may have less adaptive social strategies and experience more difficulties in creating or sustaining the positive relationships that are emphasized by the intervention, because they feel less powerful and self-confident (Duncan 2004). They may also have problems with trusting others' intentions; this mistrust may extend into peer situations that are central in anti-bullying interventions, such as establishing contact between bystanders and victims (Salmivalli et al. 2011). Less trusting victims may question their peers' sincerity in creating positive social relationships with them when this contrasts with their behavior before the intervention (Ladd and TroopGordon 2003). Hence, these children might remain socially isolated from peers and have therefore more difficulty recruiting support. Alternatively, cold or hostile parents might be less likely to support their victimized children, or to notice or report their children's victimization, and teachers would then be less likely to intervene.

\section{Limitations and Suggestions for Future Research}

In interpreting our results, some limitations need to be kept in mind. First, most measures were based on children's self-reports, possibly resulting in inflated associations due to shared method variance. Further, self-reports of victimization might be influenced by different conceptions of what constitutes victimization and children's abilities to remember instances of victimization. Therefore, it is important to note that in this study, we measured children's perceptions of victimization. Future studies could incorporate multiple informants to elucidate whether similar trajectories arise when peers or teachers report on victimization.

Moreover, when examining potential risks for persistent victimization, we used assessments from the beginning of the intervention. However, these risks may change over time; for 
example, victims might become more self-confident during an intervention. Dynamic models could elucidate change over time in risk factors and associations with victimization trajectories, and would be a valuable application in future work.

The current study did not go beyond children and their individual relationships. Characteristics at other levels, such as the classroom, also predict victimization (e.g., Cook et al. 2010; Hong and Espelage 2012). Although tentative, such characteristics might contribute information as to why some children benefit more from an intervention. However, in every classroom where there was a persistent victim, there was also at least one victim on the decreasing trajectory (details available from first author), underlining that within-group differences - individual characteristics - are important for persistent victimization.

Given the lack of a persistent-victims group in our control sample, we cannot say with certainty whether differences between persistent and decreasing groups indeed result from the intervention. However, we found that the trajectory groups did not differ in their victimization histories preceding the data collection as assessed at T1 (details available from first author). This lends support to the assumption that changes in victimization over time were due to KiVa.

The group-based trajectory approach assumes a finite number of distinct, developmentally homogeneous trajectory groups, but it cannot be determined with certainty whether these different groups exist in reality or whether they are a statistical artifact (Skardhamar 2010). That is, although latent classes may reflect qualitatively different meaningful realworld population subgroups, the distribution of true scores could also be continuous, and subgroups merely quantitatively different. Further, it can be difficult to arrive at a definite solution concerning the number of trajectories. That said, our solutions were not only supported by the fit indices but were also theoretically meaningful.

Some of our findings raised questions that went beyond the scope of this study, such as whether the effect of parent-child relationship quality indeed predicts persistent victimization through its effect on children's behaviors towards and interactions with peers. Findings from indirect effect models are needed to shed light on these mechanisms. In addition, risk characteristics do not operate in isolation, but interact with each other in their effects on victimization. To get a more comprehensive view of the contexts in which risk characteristics are particularly harmful, interactions between risk characteristics in their effects on victimization need to be examined in future research.

\section{Implications}

The findings of this study have implications for anti-bullying interventions. The existence of persistent victims shows that even during an otherwise effective intervention, children can be victimized for a prolonged period. To prevent persistency, teachers need tools to recognize victims earlier and systematically tackle existing cases of victimization. In addition, interventions may also benefit from strategies to decrease victimization for particularly vulnerable children by improving peer dynamics more generally and including tailored strategies to stimulate social integration of rejected, anxious, or withdrawn children or those with a problematic family context. Such strategies could focus on safe interactions between these children and prosocial peers, to create bonds that increase resilience to peer victimization and to socio-emotional problems (Reijntjes et al. 2010). Further, they could tackle children's potential interpretation bias, adapting effective strategies from methods based on social information processing models, such as positive interpretation modification training. Finally, interventions may benefit from a parental component to broaden the scope of the intervention, such as including parent-teacher meetings and actively involving parents (Ttofi and Farrington 2011).

\section{Compliance with Ethical Standards}

Funding The implementation and evaluation of KiVa in the Netherlands was financed by grants from the Dutch Ministry of Education (Onderwijs Bewijs, ODB10025) and the Dutch Science Foundation (NWO VICI 453-14-016). The two last authors coordinated the implementation and evaluation. Program dissemination is done by a company (www. kivaschool.nl).

Conflict of Interest The authors declare that they have conflict of interest.

Ethical Standards and Informed Consent At the time of data collection (2012-2014) an Internal Review Board was not established at the Department of Sociology and the Dutch law did not require IRB permission for this type of research. Informed consent was obtained from all individual participants and schools included in the study.

Research Involving Human Participants and/or Animals All procedures performed in studies involving human participants were in accordance with the ethical standards of the institutional and/or national research committee and with the 1964 Helsinki declaration and its later amendments or comparable ethical standards. This article does not contain any studies with animals performed by any of the authors.

Open Access This article is distributed under the terms of the Creative Commons Attribution 4.0 International License (http:// creativecommons.org/licenses/by/4.0/), which permits unrestricted use, distribution, and reproduction in any medium, provided you give appropriate credit to the original author(s) and the source, provide a link to the Creative Commons license, and indicate if changes were made.

\section{References}

Achenbach, T. M. (1991). Manual for the youth self-report and 1991 profile. Burlington: Department of Psychiatry, University of Vermont. 
Arrindell, W. A., Emmelkamp, P. M. G., Brilman, E., \& Monsma, A. (1983). Psychometric evaluation of an inventory for assessment of parental rearing practices. Acta Psychiatrica Scandinavica, 67, 163177.

Axford, N., Farrington, D. P., Clarkson, S., Bjornstad, G. J., Wrigley, Z., \& Hutchings, J. (2015). Involving parents in school-based programmes to prevent and reduce bullying: What effect does it have? Journal of Children's Services, 10, 242-251.

Bandura, A. (1971). Social learning theory. New York, NY: General Learning Corporation.

Barker, E. D., Arseneault, L., Brendgen, M., Fontaine, N., Maughan, B., Boivin, M., et al. (2008a). Joint development of bullying and victimization in adolescence: Relations to delinquency and self-harm. Journal of the American Academy of Child and Adolescent Psychiatry, 47, 1030-1038.

Barker, E. D., Boivin, M., Brendgen, M., Fontaine, N., Arseneault, L., Vitaro, F., ... Tremblay, R. E. (2008b). Predictive validity and early predictors of peer-victimization trajectories in preschool. Archives of General Psychiatry, 65, 1185-1192.

Biggs, B. K., Vernberg, E., Little, T. D., Dill, E. J., Fonagy, P., \& Twemlow, S. W. (2010). Peer victimization trajectories and their association with children's affect in late elementary school. International Journal of Behavioral Development, 34, 136-146.

Boivin, M., Petitclerc, A., Feng, B., \& Barker, E. D. (2010). The developmental trajectories of peer victimization in middle to late childhood and the changing nature of their behavioral correlates. MerrillPalmer Quarterly, 56, 231-260.

Bowlby, J. (1969). Attachment and loss volume 1: Attachment (2nd ed.). New York, NY: Basic Books.

Brendgen, M., \& Poulin, F. (2018). Continued bullying victimization from childhood to young adulthood: A longitudinal study of mediating and protective factors. Journal of Abnormal Child Psychology, 46, 27-39.

Chorpita, B. F., Yim, L., Moffitt, C., Umemoto, L. A., \& Francis, S. E. (2000). Assessment of symptoms of DSM-IV anxiety and depression in children: A revised child anxiety and depression scale. Behaviour Research and Therapy, 38, 835-855.

Cook, C. R., Williams, K. R., Guerra, N. G., Kim, T. E., \& Sadek, S. (2010). Predictors of bullying and victimization in childhood and adolescence: A meta-analytic investigation. School Psychology Quarterly, 25, 65-83.

Copeland, W. E., Wolke, D., Angold, A., \& Costello, E. J. (2013). Adult psychiatric outcomes of bullying and being bullied by peers in childhood and adolescence. JAMA Psychiatry, 70, 419-426.

Duncan, R. D. (2004). The impact of family relationships on school bullies and their victims. In D. L. Espelage \& S. M. Swearer (Eds.), Bullying in American schools: A social-ecological perspective on prevention and intervention (pp. 227-244). Mahwah, NJ: Lawrence Erlbaum Associates.

Evans, C. B. R., Fraser, M. W., \& Cotter, K. L. (2014). The effectiveness of school-based bullying prevention programs: A systematic review. Aggression and Violent Behavior, 19, 532-544.

Fonagy, P., Twemlow, S. W., Vernberg, E. M., Nelson, J. M., Dill, E. J., Little, T. D., \& Sargent, J. A. (2009). A cluster randomized controlled trial of child-focused psychiatric consultation and a school systems-focused intervention to reduce aggression. Journal of Child Psychology and Psychiatry and Allied Disciplines, 50, 607-616.

Furmark, T., Tillfors, M., Everz, P.-O., Marteinsdottir, I., Gefvert, O., \& Fredrikson, M. (1999). Social phobia in the general population: Prevalence and sociodemographic profile. Social Psychiatry and Psychiatric Epidemiology, 34, 416-424.

Garandeau, C. F., Lee, I. A., \& Salmivalli, C. (2018). Decreases in the proportion of bullying victims in the classroom: Effects on the adjustment of remaining victims. International Journal of Behavioral Development, 42, 64-72.
Giesbrecht, G. F., Leadbeater, B. J., \& Macdonald, S. W. S. (2011). Child and context characteristics in trajectories of physical and relational victimization among early elementary school children. Development and Psychopathology, 23, 239-252.

Graham, S., \& Juvonen, J. (1998). Self-blame and peer victimization in middle school: An attributional analysis. Developmental Psychology, 34, 587-599.

Guerra, N. G., Williams, K. R., \& Sadek, S. (2011). Understanding bullying and victimization during childhood and adolescence: A mixed methods study. Child Development, 82, 295-310.

Haltigan, J. D., \& Vaillancourt, T. (2014). Joint trajectories of bullying and peer victimization across elementary and middle school and associations with symptoms of psychopathology. Developmental Psychology, 50, 2426-2436.

Heron, J., Croudace, T. J., Barker, E. D., \& Tilling, K. (2015). A comparison of approaches for assessing covariate effects in latent class analysis. Longitudinal and Life Course Studies, 6, 420-434.

Hodges, E. V., \& Perry, D. G. (1999). Personal and interpersonal antecedents and consequences of victimization by peers. Journal of Personality and Social Psychology, 76, 677-685.

Hong, J. S., \& Espelage, D. L. (2012). A review of research on bullying and peer victimization in school: An ecological system analysis. Aggression and Violent Behavior, 17, 311-322.

Juvonen, J., \& Galván, A. (2008). Peer influence in involuntary social groups: Lessons from research on bullying. In M. Prinstein \& K. Dodge (Eds.), Peer influence processes among youth (pp. 225-244). New York, NY: Guilford Press.

Kärnä, A., Voeten, M., Little, T. D., Poskiparta, E., Kaljonen, A., Salmivalli, C., et al. (2011). A large-scale evaluation of the KiVa antibullying program: Grades 4-6. Child Development, 82, 311-330.

Kokkinos, C. M. (2013). Bullying and victimization in early adolescence: Associations with attachment style and perceived parenting. Journal of School Violence, 12, 174-192.

Kretschmer, T., Veenstra, R., Branje, S. J. T., Dekovic, M., Koot, H. M., Meeus, W. H. J., Reijneveld, S. A., Vollebergh, W. A. M., \& Oldehinkel, A. J. (2018). How competent are adolescent bullying perpetrators and victims in mastering normative developmental tasks in early adulthood? Journal of Abnormal Child Psychology, 46, 41-56.

Lo, Y., Mendell, N. R., \& Rubin, D. B. (2001). Testing the number of components in a normal mixture. Biometrika, 88, 767-778.

Marks, P. E. L., Cillessen, A. H. N., \& Crick, N. R. (2012). Popularity contagion among adolescents. Social Development, 21, 501-521.

Merrell, K. W., Gueldner, B. A., Ross, S. W., \& Isava, D. M. (2008). How effective are school bullying intervention programs? A metaanalysis of intervention research. School Psychology Quarterly, $23,26-43$.

Miers, A. C., Blö, A. W., Bögels, S. M., \& Westenberg, P. M. (2008). Interpretation bias and social anxiety in adolescents. Journal of Anxiety Disorders, 22, 1462-1471.

Morrow, M. T., Hubbard, J. A., Barhight, L. J., \& Thomson, A. K. (2014). Fifth-grade children's daily experiences of peer victimization and negative emotions: Moderating effects of sex and peer rejection. Journal of Abnormal Child Psychology, 42, 1089-1102.

Muthén, K., \& Muthén, B. O. (2015). Mplus user's guide (7th ed.). Los Angeles, CA: Múthen \& Múthen.

Olweus, D. (1996). The revised olweus bully/victim questionnaire. Bergen, Norway: Research Center for Health Promotion (HEMIL Center), University of Bergen.

Reijntjes, A., Kamphuis, J. H., Prinzie, P., Boelen, P. A., Van Der Schoot, M., \& Telch, M. J. (2011). Prospective linkages between peer victimization and externalizing problems in children: A meta-analysis. Aggressive Behavior, 37, 215-222.

Reijntjes, A., Kamphuis, J. H., Prinzie, P., \& Telch, M. J. (2010). Peer victimization and internalizing problems in children: A meta- 
analysis of longitudinal studies. Child Abuse \& Neglect, 34, 244 252.

Rosenberg, M. (1965). Society and the adolescent self-image. Princeton, NJ: Princeton University Press.

Poulin, F., \& Chan, A. (2010). Friendship stability and change in childhood and adolescence. Developmental Review, 30, 257-272.

Saarento, S., Boulton, A. J., \& Salmivalli, C. (2014). Reducing bullying and victimization: Student- and classroom-level mechanisms of change. Journal of Abnormal Child Psychology, 43, 1-16.

Salmivalli, C., \& Isaacs, J. (2005). Prospective relations among victimization, rejection, friendlessness, and children's self- and peer-perceptions. Child Development, 76, 1161-1171.

Salmivalli, C., Kärnä, A., \& Poskiparta, E. (2011). Counteracting bullying in Finland: The KiVa program and its effects on different forms of being bullied. International Journal of Behavioral Development, $35,405-411$.

Sapouna, M., Wolke, D., Vannini, N., Watson, S., Woods, S., Schneider, W., et al. (2010). Virtual learning intervention to reduce bullying victimization in primary school: A controlled trial. Journal of Child Psychology and Psychiatry, 51, 104-112.

Sheppard, C. S., Giletta, M., \& Prinstein, M. J. (2018). Peer victimization trajectories at the adolescent transition: Associations among chronic victimization, peer-reported status, and adjustment. Journal of Clinical Child \& Adolescent Psychology, https://doi.org/10.1080/ 15374416.2016.1261713.
Simonds, J., \& Rothbart, M. K. (2004). The Temperament in Middle Childhood Questionnaire (TMCQ): A computerized self-report measure of temperament for ages 7-10. Poster session presented at the Occasional Temperament Conference, Athens, GA.

Skardhamar, T. (2010). Distinguishing facts and artifacts in group-based modeling. Criminology, 48, 295-320.

Thornberg, R., Tenenbaum, L., Kris, V., Joel, M., Tomas, J., \& Gina, V. (2012). Bystander motivation in bullying incidents: To intervene or not to intervene? Western Journal of Emergency Medicine, 13, 247 252.

Ttofi, M. M., \& Farrington, D. P. (2011). Effectiveness of school-based programs to reduce bullying: A systematic and meta-analytic review. Journal of Experimental Criminology, 7, 27-56.

Veenstra, R. (2015). Signaleren en tegengaan van pesten: het KiVa antipestprogramma. Eindrapportage voor Onderwijs Bewijs [Signaling and reducing bullying in schools: The KiVa antibullying program. Final report for Education Effectiveness Research]. The Hague: Ministry of Education, Culture and Science. Retrieved from: http://tinyurl.com/KiVa-onderwijsbewijs

Yeager, D. S., Fong, C. J., Lee, H. Y., \& Espelage, D. L. (2015). Declines in efficacy of anti-bullying programs among older adolescents: Theory and a three-level meta-analysis. Journal of Applied Developmental Psychology, 37, 36-51. 